\title{
COMPOSIÇÃO CENTESIMAL DE DIFERENTES FARINHAS DE AMÊNDOA
}

\section{Thaiza Serrano Pinheiro de Souza ${ }^{1}$; Joel Pimentel de Abreu ${ }^{1}$; Henrique Monteiro de Abreu ${ }^{2}$; Anderson Junger Teodoro ${ }^{1,2}$; Maria Gabriela Bello Koblitz ${ }^{1,2}$ (thaizasps@ gmail.com)}

${ }^{1}$ Programa de Pós Graduação em Alimentos e Nutrição (PPGAN) - Universidade Federal Estadual do Rio de Janeiro (UNIRIO)

${ }^{2}$ Escola de Nutrição - Universidade Federal Estadual do Rio de Janeiro (UNIRIO)

Amêndoas são alimentos vegetais altamente nutritivos, sendo consideradas fontes de lipídios (48$67 \%$ ), de proteína (12-22\%) e carboidratos (20\%) para a dieta. Trata-se de um fruto adaptado para a região do Mediterrâneo, sendo produzido comercialmente pelos EUA (82\%), Europa (8\%), Austrália (7\%), Turquia (1\%), Chile (1\%) e outros (1\%). Há um crescente interesse em seu consumo por ser considerado um alimento saudável, já que traz benefícios à saúde ao ser consumido regularmente. $\mathrm{O}$ objetivo deste estudo foi comparar a composição centesimal de farinhas de amêndoa de origem chilena, comercializada no Brasil $(\mathrm{CH})$ e produzida na Califórnia (CA), o maior produtor mundial de amêndoas. Um quilo de cada farinha utilizada foi adquirido no comércio das cidades do Rio de Janeiro e de Camarillo (EUA) respectivamente, e foram avaliadas quanto ao teor de: umidade, por secagem direta em estufa a $105^{\circ} \mathrm{C}$; lipídios, por extração direta em Soxleht; proteínas, pelo método de Kjeldahl; resíduo mineral fixo, por incineração em mufla a $550{ }^{\circ} \mathrm{C}$ e carboidratos, por diferença. Todas as análises seguiram a metodologia citada por Adolfo Lutz (2008) e foram realizadas em quintuplicata. Para as análises estatísticas foi utilizada a ANOVA ao nível de 5\% de significância. Quanto aos resultados obtidos, tem-se que: o teor de umidade foi maior na amostra $\mathrm{CH}$, com 4,66 \pm 0,26\% enquanto a farinha de amêndoa CA apresentou um teor de 3,42 $\pm 00,8 \%$; assim como o teor de proteínas, onde $\mathrm{CH}$ mostrou um teor de 24,28 \pm 0,38\% (base seca) e 23,15 $\pm 017 \%$ (base úmida) e CA com 22,00 $\pm 0,72 \%$ (base seca) e 21,24 $\pm 0,69 \%$ (base úmida). Quanto ao teor de cinzas e carboidratos, a amostra CA apresentou teores mais elevados, como pode ser observado a seguir: teor de cinzas, $\mathrm{CH}$ com teor de $2,84 \pm 0,11 \%$ (base seca) e $2,71 \pm 0,11 \%$ (base úmida) e CA 2,94 $\pm 0,01 \%$ (base seca) e 2,84 $\pm 0,01 \%$ (base úmida) e quanto ao teor de carboidratos, para $\mathrm{CH}$ tem-se 9,76\% (base seca) e 13,75\% (base úmida) e para CA tem-se 11,42\% (base seca) e 14,34\% (base úmida). Quanto ao teor de lipídios, não houve diferença estatística e observou-se os seguintes resultados: $\mathrm{CH}$ com $58,45 \pm 0,18 \%$ (base seca) e $55,73 \pm 0,17 \%$ (base úmida) e na amostra CA foram observados teores de 60,22 $\pm 0,09 \%$ (base seca) e 58,16 $\pm 0,09 \%$ (base úmida). Estas diferenças observadas se devem ao fato de que a composição de nutrientes é dependente do genótipo, de fatores ambientais, da região de cultivo, dos métodos de cultivo, das condições climáticas que variam entre os anos de colheita ou ainda das interações destes fatores. A partir deste estudo pode-se afirmar que dependo do local de cultivo haverá diferenças na composição final de cada farinha de amêndoa, mesmo que sutis. Palavras-chave: amêndoa; composição; diferentes origens. 